\title{
Teaching hydrogeology: a review of current practice
}

\author{
T. Gleeson ${ }^{1}$, D. M. Allen ${ }^{2}$, and G. Ferguson ${ }^{3}$ \\ ${ }^{1}$ Department of Civil Engineering, McGill University, Montreal, Quebec, Canada \\ ${ }^{2}$ Department of Earth Sciences, Simon Fraser University, Burnaby, BC, V5A 1S6, Canada \\ ${ }^{3}$ Department of Civil and Geological Engineering, University of Saskatchewan, Saskatoon, Saskatchewan, Canada
}

Correspondence to: T. Gleeson (tom.gleeson@mcgill.ca)

Received: 12 January 2012 - Published in Hydrol. Earth Syst. Sci. Discuss.: 20 January 2012

Revised: 11 June 2012 - Accepted: 15 June 2012 - Published: 18 July 2012

\begin{abstract}
Hydrogeology is now taught in a broad spectrum of departments and institutions to students with diverse backgrounds. Successful instruction in hydrogeology thus requires a variety of pedagogical approaches depending on desired learning outcomes and the background of students. We review the pedagogical literature in hydrogeology to highlight recent advances and analyze a 2005 survey among 68 hydrogeology instructors. The literature and survey results suggest there are only $\sim 15$ topics that are considered crucial by most hydrogeologists and $>100$ other topics that are considered crucial by some hydrogeologists. The crucial topics focus on properties of aquifers and fundamentals of groundwater flow, and should likely be part of all undergraduate hydrogeology courses. Other topics can supplement and support these crucial topics, depending on desired learning outcomes. Classroom settings continue to provide a venue for emphasizing fundamental knowledge. However, recent pedagogical advances are biased towards field and laboratory instruction with a goal of bolstering experiential learning. Field methods build on the fundamentals taught in the classroom and emphasize the collection of data, data uncertainty, and the development of vocational skills. Laboratory and computer-based exercises similarly build on theory, and offer an opportunity for data analysis and integration. The literature suggests curricula at all levels should ideally balance field, laboratory, and classroom pedagogy into an iterative and integrative whole. An integrated, iterative and balanced approach leads to greater student motivation and advancement of theoretical and vocational knowledge.
\end{abstract}

\section{Introduction}

In the last thirty years, hydrogeology has emerged as a core course in geoscience departments as well as civil, geological and environmental engineering departments (Pederson, 1987; Tinker, 1989; Santi and Higgins, 2005). In addition to providing foundational training to geoscientists and engineers, hydrogeology courses are often taken as electives by students from a variety of backgrounds including biology, environmental science, geography, urban planning and bioresource engineering (to name the backgrounds of students in the authors' classes in the last year). Hydrogeology is also taught as a component of courses in other departments such as forestry and catchment science as well as interdisciplinary centers examining water, sustainability, and climate change issues. In short, hydrogeology is now taught in a broad spectrum of departments to students with very diverse backgrounds. Demand for hydrogeology instruction has grown because of strong employment prospects for trained hydrogeologists and the growing recognition of groundwater in other disciplines. Data from the US Department of Labor and the American Geological Institute suggest the job market for hydrogeologists in the "green economy" (Bahr, 2009) is strong and will continue to be so in the future (Santi and Higgins, 2005). Hydrogeology has even been called "recession-proof" (Coontz, 2008). The growing recognition of the interactions of groundwater with surface water hydrology, ecology and other disciplines (Alley et al., 2002; Sophocleous, 2002) has also contributed to increased demand for hydrogeology instruction.

Hydrogeology is largely an applied science, and instructors grapple with the balance between teaching vocational skills, which increase employability, and teaching theoretical 
knowledge, which is essential for more complex problem solving. Teaching hydrogeology is further complicated by three additional issues. Hydrogeology necessitates a great breadth of background knowledge. Learning outcomes have traditionally been narrowly targeted specific to hydrogeology, but students with a more diverse background may require these to be broader. It is difficult to balance focusing on more traditional content specific to hydrogeology with a more interdisciplinary approach (Coontz, 2008). Definition of appropriate content and course delivery is further complicated by the delivery of hydrogeology courses by different departments and institutions as well as a variety of educational settings (field, laboratory, and classroom), each with its own complications.

The field of hydrogeology is intertwined with global change. Groundwater issues exist in the fields of sustainability (Foster and Chilton, 2003; Gleeson et al., 2010), food production (Giordano, 2009), climate change (Green et al., 2011), energy and metal resources (Banks et al., 1997; McCray and Thyne, 2009), all of which are critical issues for the future of our planet. The need for strong hydrogeological input in the discourse of global change demands rigorously and broadly trained hydrogeologists who can participate in this conversation with people from a variety of backgrounds. Developing an educational framework that allows for exposure to the multidisciplinary nature of current hydrogeological problems, incorporation of emerging techniques and coverage of the scientific fundamentals are key to dealing with our planet's groundwater issues.

This paper summarizes the challenges of teaching undergraduate hydrogeology in an experiential learning context and offers a pragmatic approach for adapting to changing demands while maintaining crucial learning outcomes. A review of the literature focuses both on crucial learning outcomes and different pedagogical approaches that have been successfully implemented for teaching hydrogeology in the classroom, the field and laboratory. Our objective is to qualitatively review, highlight and promote the diversity of pedagogical advances and applications that have occurred largely in the last fifteen years. We draw primarily from the Journal of Geoscience Education (previously called the Journal of Geological Education before 1996), because articles on hydrogeology are not common in engineering education journals. Figure 1 shows how the rate of publishing papers on hydrogeology pedagogy increased dramatically in the mid 1990s. We also analyze unpublished data from a survey among hydrogeology instructors $(n=68)$ that were asked what topics should be included in an undergraduate hydrogeology course. The voluntary survey was conducted online with pull-down tabs before a 2005 workshop entitled "Teaching Hydrogeology in the 21st Century", organized by the National Association of Geoscience Education (raw data available at: http://serc.carleton.edu/NAGTWorkshops/ hydrogeo/index.html). We summarize the results, highlighting the range of topics considered critical for hydrogeology

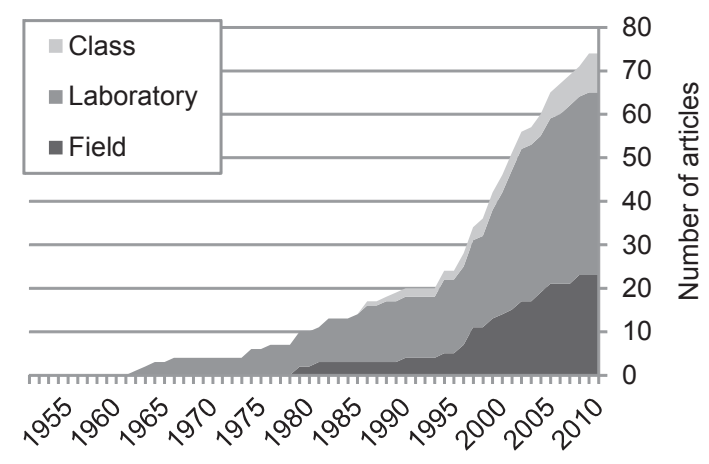

Fig. 1. Articles in the Journal of Geological Education (pre-1996) or Journal of Geoscience Education (post-1996) focusing on hydrogeology pedagogy either in the classroom, laboratory or field.

courses. We conclude with ideas for integrating learning in the field, laboratory and classroom settings, emphasizing the importance of experiential learning, which in recent years has become a focus in pedagogy at all levels and across many disciplines.

We focus on introductory physical hydrogeology, recognizing that many institutions may only offer one course in this field while others may offer two or more such as aqueous geochemistry, contaminant transport, field school or modeling (Pederson, 1987). We acknowledge that hydrogeology is taught in a variety of departments and institutions which have a large range of ability and interest in supporting pedagogical advancement in hydrogeology. For simplicity we use the term "hydrogeology", which can be considered equivalent herein to groundwater hydrology, geohydrology or groundwater engineering for the purposes of this pedagogical article. We also use "geoscience" and "engineering" as short forms for earth science and geology and for civil, geological and environmental engineering, respectively.

\section{Evolving student backgrounds}

The growing diversity of students taking introductory hydrogeology requires instructors to carefully scrutinize and perhaps relax prerequisites to allow for broad student backgrounds. Understanding these various backgrounds will allow realistic learning outcomes to be set (see next section) and help develop consistent expectations for both the instructor and the students. A greater student diversity may mean that specific course requirements may be met by incoming students, yet their overall background can be vastly different. This presents a particular challenge because we commonly teach concepts using examples that relate to topics students may have covered in previous courses - sometimes not those courses listed as prerequisites. For example, students who have taken stratigraphy and sedimentology (i.e. geoscience majors) will associate hydrostratigraphy concepts readily, while engineering majors will likely have 
strong skills in partial differential equations. The physical geography major, however, may have a strong background in climatology and hydrology. This diversity of backgrounds means that the instructor must be adaptable and gauge expectations accordingly, particularly during assessment, so that students are tested specifically on what they have learned in the course and how that knowledge relates to their individual background. This is the essence of experiential learning as will be discussed later.

Introductory hydrogeology courses are normally offered in the $3 \mathrm{rd}$ or 4 th year of an undergraduate program. At a minimum, introductory physical hydrogeology requires students to have some basic knowledge and skills in three subject areas: (1) physical geology including basic rock types, structural features, stratigraphy, geological maps and cross-sections; (2) Newtonian mechanics and well-developed physics-based problem solving skills; and (3) an appropriate level of mathematics including algebra, trigonometry, and introductory calculus. For an introductory course in hydrogeology, these prerequisites need be no higher than a first year level. For those introductory courses including aspects of aqueous geochemistry and contamination, the fundamentals of chemistry should be well in hand.

\section{What are the crucial learning outcomes?}

Wagener et al. (2012) note that the role of hydrology as a diverse discipline encompassing the terrestrial, oceanic and atmospheric components of the hydrologic system has expanded over time to address increasingly larger-scale problems in a more interdisciplinary fashion. They note that in order to train holistic hydrologists, a coherent view of the discipline among educators is needed, yet this is difficult in the diverse discipline of hydrology. Hydrogeologists are required to possess a wide spectrum of knowledge and skills, because this sub-discipline of hydrology is itself multidisciplinary. Aquifers are often studied using a variety of multidisciplinary tools (geological, geophysical, geochemical, mathematical, and computational) demanding some level of competency and knowledge in their application. However, all of these skills and topics cannot practically be taught in a single undergraduate course. Therefore, a challenge to teaching hydrogeology is choosing which topic or skill to include or emphasize in a given course or lecture, while making the best use of time and resources. Additionally, hydrogeology instructors may find it challenging to design (or perhaps modify) a "one size fits all" course that provides foundational training to students with diverse backgrounds. Each instructor will have different desired learning outcomes depending in part on their background, department and institution. And each student will have a different learning style and background. This suggests that no singular, prescriptive pedagogy for hydrogeology is possible, useful or perhaps required.
The crucial topics or skills that should be taught in a hydrogeology class have been discussed in the literature (Table 1) as well as at workshops, conferences and symposia of the National Association of Geoscience Education and the Association of Engineering Geologists. Tinkler (1989), Santi and Higgins (2005), Siegel (2008) and Neuman (2009) list or discuss topics they consider crucial for a hydrogeology class based on their personal experience and discussions with other professionals (Table 1). Results of the 2005 survey at a workshop of the National Association of Geoscience Education indicate that few topics are considered crucial by most hydrogeologists, while many other topics are considered crucial by only some hydrogeologists (Fig. 2). Participants were given three choices: (1) topic considered crucial, can not be missed; (2) topic covered, would consider shortening or eliminating; (3) not covered. Only 15 topics are considered crucial by $>75 \%$ of hydrogeology instructors. These top 15 crucial topics are listed in Fig. 3 and focus on properties of aquifers and fundamentals of groundwater flow. Overall, the topics considered crucial by $>75 \%$ of hydrogeologists are generally consistent with topics and skills recommended by Tinkler (1989), Santi and Higgins (2005) and Siegel (2008). An examination of topics covered in textbooks over the past several decades (Davis and DeWiest, 1966; Freeze and Cherry, 1979; Todd, 1980; Domenico and Schwartz, 1998; Fetter, 2001; Schwartz and Zhang, 2003; Hiscock, 2005; Younger, 2007) supports this idea, as similar topics are emphasized in each of these books. The consistency between survey results, previous recommendations and textbooks suggests these top 15 topics should likely be part of all undergraduate hydrogeology courses.

More than 100 other topics are considered crucial by some hydrogeologists (Fig. 2; Fig. S1 in the Supplement), suggesting a large variety of topics is taught in undergraduate hydrogeology classes. These additional topics are not considered crucial by most hydrogeology instructors and cover a diverse range including the hydrologic cycle, properties of water and aquifers, fundamentals of groundwater flow, equations of groundwater flow, unsaturated zone hydrology, evaluation of groundwater resources, regional groundwater flow, groundwater chemistry and groundwater geology. Many of these topics are covered in the textbooks examined, but, interestingly, newer and more interdisciplinary topics such as sustainability, source water protection or groundwater and ecosystems generally receive little attention, even in newer textbooks. Other topics can supplement and support these crucial topics, depending on desired learning outcomes. In the next section pedagogical advances in the class, field and laboratory that can cover the various topics are discussed. 
Table 1. Critical knowledge and skills for practicing hydrogeologists.

$$
\begin{aligned}
& \text { Santi and Higgins (2005) } \\
& \text { - Design of subsurface investigations } \\
& \text { - Three-point problem solution } \\
& \text { - Flow net construction and analysis } \\
& \text { - Oral and written communication skills } \\
& \text { - Use of Darcy's law and calculation of groundwater } \\
& \text { velocity } \\
& \text { - Hydraulic conductivity and intrinsic permeability, } \\
& \text { calculation and measurement methods } \\
& \text { - Aquifer types and groundwater occurrence } \\
& \text { - Storativity and transmissivity, calculation and } \\
& \text { measurement methods } \\
& \text { - Vertical groundwater gradients and flow } \\
& \text { - Water budget and hydrologic cycle } \\
& \text { - Basic statistics and probabilistic methods } \\
& \text { - Geographic information systems } \\
& \text { - Aquifer testing and analysis }
\end{aligned}
$$

\section{Siegel (2008)}

- "Do not push the data farther than they can be pushed and be honest with respect to what can be done"

- Darcy's law needs to be understood at the "gut" level

- Potentiometric surfaces are different from the water table

- Surface water is an "outcrop" of the water table

- Groundwater occurs in nested flow systems, separated by hydraulic boundaries

- Contour using your head, and not your computer

- Explore simple bivariate plots as an analysis tool

And for courses including geochemistry

- Groundwater chemistry is predictable from first principles

- Chemical oxidation and reduction control many important groundwater and contaminant chemical compositions

- As a working approximation, contaminant plumes should be considered narrow and no wider than a few times the width of the source at their heads

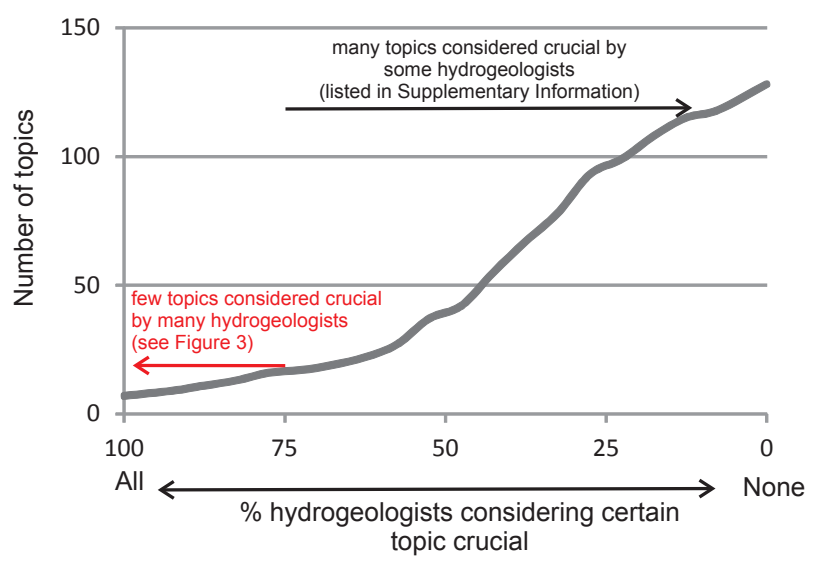

Fig. 2. Cumulative distribution of responses of hydrogeology instructors $(n=68)$ asked what topics should be included in an undergraduate hydrogeology course. The voluntary survey is described in the Introduction. The 15 topics that $>75 \%$ of hydrogeologists consider crucial are list in Fig. 3. The $>100$ other topics that some hydrogeologists consider crucial are listed in Fig. S1 in the Supplement.

\section{Advances in pedagogical approaches}

In this section, we review the literature on pedagogical approaches for hydrogeology. Web-based resources are also available. For example, the website "Teaching Hydrogeology in the 21st Century", hosted by the National Association of Geoscience Education and Carleton College (http://serc. carleton.edu/NAGTWorkshops/hydrogeo/index.html), is a significant resource for pedagogical ideas including activities and assignments, visualizations, internet resources, hydrogeology analogies and articles accessible to undergraduate hydrogeology students. There are also a number of online videos (e.g. YouTube or Vimeo) that are worth exploring for undergraduate hydrogeology courses.

Throughout this section, we refer to experiential learning, which, simply put, is learning by experience. Experiential learning is defined as "the process whereby knowledge is created through the transformation of experience. Knowledge results from the combination of grasping and transforming experience" (Kolb, 1984). In practice, experiential learning is characterized as inductive, learner-centered, and activityoriented (Saskatoon Public Schools, 2009, from http://olc. spsd.sk.ca/de/pd/instr/experi.html; Ngambeki et al., 2012). Inductive reasoning is a form of reasoning that makes generalizations based on individual instances. Personalized reflection about an experience (learner-centered) and the formulation of plans to apply learning to other contexts (activityoriented) are critical factors in effective experiential learning. 


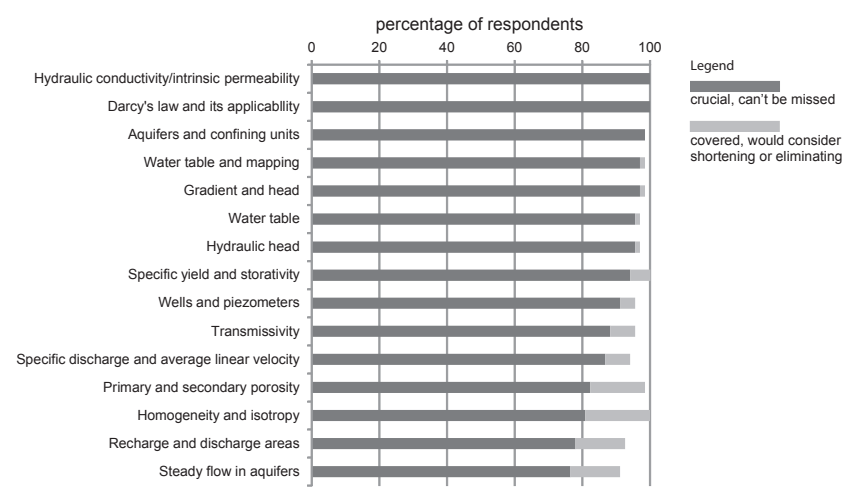

Fig. 3. The top 15 most important topics for an undergraduate hydrogeology course according to a survey conducted in 2005 among academic hydrogeologists $(n=68)$. A graphic compilation of all topics in the survey can be found in Fig. S1 in the Supplement.

\subsection{Teaching hydrogeology in the classroom}

Field and laboratory pedagogy are important, but the essential theoretical underpinnings of hydrogeology are taught in the classroom. Amazingly, the literature discussing classroom pedagogy is limited (Fig. 1). A few recent articles have suggested specific active learning activities that could be useful. Siegel and McKenzie (2004) discuss a project of a fictional contamination incident that divides the class into three groups and culminates in a one-day mock trial. Singha (2008) presents a simple, inexpensive demonstration (using a juice container!), which can be used to help students visualize the interplay between stresses and fluid pressure when pumping a confined aquifer. Rodhe (2012) describes mobile physical models, demonstrations and experiments that are suitable for lectures and that promote discussion and stimulate student engagement. Below we describe a semester-long design project developed by Neupaurer (2008), which integrates classroom theory with weekly assignments.

In addition to providing a venue for emphasizing fundamental knowledge, a classroom setting allows for tackling multidisciplinary topics. Student discourse can enrich learning through the sharing of ideas, particularly when their backgrounds are diverse. This too is part of experiential learning and often allows for more complex problem solving. For example, a discussion about watersheds will bring a variety of issues to light in a classroom that has mixed academic backgrounds, particularly when a few biologists in the room can add to topics encompassing aquatic ecology.

Since the number of papers focusing on classroom pedagogy is limited and the classroom is important for emphasizing fundamental knowledge, more papers could be written on classroom pedagogy. These could follow the example of Mays (2010), who explicitly discusses a lesson plan with a reading assignment and classroom presentation including terminology, key concepts, and modeling approach that will be used in the subsequent class meeting in the computer laboratory. More articles could be written that offer suggestions to engage students in active learning like Siegel and McKenzie (2004), Singha (2008), Pathirana et al. (2012), Ngambeki et al. (2012) and Rodhe (2012).

\subsection{Teaching hydrogeology in the field}

Teaching hydrogeology and hydrogeology research skills in the field is crucial because this is the essential source of all data (Fletcher, 1994). Integration of the field component of the course is frequently the most difficult due to the availability of field sites and time constraints. The time of year when a course is offered can also present a significant challenge in some areas where field activities are limited during the winter. In addition, acquiring data necessitates having access to a suitable field site. This can be a challenge in areas with few wells or where well access is restricted (Sanders, 1998). Three avenues for teaching hydrogeology in the field are field trips, on- or near-campus sites, and dedicated field school sites. Each method is complicated by difficulties in data acquisition.

Field trips are generally considered sightseeing tours where students examine features, perhaps make a few measurements, and take notes. Even a simple walk around campus can lead to discussion about local topography, geology and likely groundwater flow pathways, without the need for measurement. To give students a greater understanding of the entire aquifer, Trop et al. (2000) recommended a short field trip that was completed in the normal allotted classroom time. The stops included a local water processing plant and an outcrop of the local aquifer rock, followed by a traverse across the valley to examine the extent of this aquifer rock (Trop et al., 2000). This exercise was designed for preservice teachers and first year students, and is an excellent introduction to the scale and concept of aquifers. Also, students felt ownership over their learning after collecting their field data.

On- or near-campus sites might include visiting geological exposures, hydrogeologic wells, and/or river systems that allow students to actively observe, test and monitor a groundwater system. Such sites can act as a focus for learning modules that strengthen independent research skills and vocational skills (Fletcher, 1994; Rimal and Stieglitz, 2000; DayLewis et al., 2006; Laton, 2006; Fryar et al., 2010). Access to these types of facilities provides a venue for developing practical skills using sampling and monitoring instruments, such as water level tapes and simple surveying equipment, or pumps and field meters for conductivity, $\mathrm{pH}$ or dissolved oxygen (Rimal and Stieglitz, 2000). Students collect useful data, which can be used later for laboratory analysis to characterize the aquifer. Using on-campus wells assumes the fortuitous situation of a useful and accessible well on campus or nearby. If this is not the case, a new well can be justified by coupling education purposes with research programs and/or 
providing a backup water supply or water quality testing site for the university (Fletcher, 1994; Rimal and Stieglitz, 2000).

Field schools occur at a dedicated location and include active learning experiments and activities. An off-campus field school can offer a more complete and in-depth field methods course because of the greater time available (typically 7-14 days). Such a field school can be paired with a traditional geology field school (Halsor et al., 1998; McKay and Kammer, 1999) or offered as a stand-alone hydrogeology field school (Horner et al., 1998). Universities that offer these field schools include University of Waterloo, Western Michigan University, University of Minnesota, Clemson University, ETH Zürich and western Canadian universities, as described below. Field schools provide opportunities for active learning, with students collecting useful quantitative data that can be used in various calculations (Lee, 1998). McKay and Kammer (1999) described neophyte hydrogeologists producing useful data and, more importantly, data analysis and interpretation after a three-day intensive field school. Creating a hydrogeology field site for education, however, is a significant financial and faculty investment (McKay and Kammer, 1999; Day-Lewis et al., 2006; Laton, 2006). The cost (10000\$-100000\$) of developing an off-campus hydrogeology site is prohibitive for most departments. However, these costs can be offset by borrowing testing equipment, using existing drilled wells, or partnering with a company at an existing site (McKay and Kammer, 1999). Alternatively, two or more universities may partner, as was done between the University of British Columbia and the University of Calgary in setting up a joint hydrogeology field school site. The site is equipped with several nested piezometers, three multi-level piezometers, a Westbay well and a pumping well. Currently, students and faculty from both these universities as well as from Simon Fraser University participate in the field school. Students are given an opportunity not only to learn vocational skills, but to apply knowledge gained through prerequisite hydrogeology courses to tackle the analysis and interpretation of the data. In addition, they meet and work with students and faculty from other universities in western Canada.

Collecting data gives students ownership over their learning and is excellent vocational training; however, very little theoretical knowledge is gained (Sanders, 1998). Efforts need to be made in the field to refer back to basic concepts or case studies taught in the classroom. For a field school, this may mean referring back to material taught during a regular semester course, or it may be possible to integrate data and concepts from a field school into a course delivered immediately thereafter. These approaches can be challenging due to scheduling of courses and, in some cases, require coordination between multiple instructors.

Each method for teaching hydrogeology in the field is useful depending on the desired instructional outcomes. Field trips are useful for introductory classes, whereas onor near-campus sites and field schools are applicable to senior /undergraduate classes, because they are more actively student-led and thus inspire student involvement. However, development of such sites is more time-intensive and possibly expensive.

\subsection{Teaching hydrogeology in the laboratory}

Teaching hydrogeology in a laboratory using personal computers as well as physical and chemical experiments is essential, because it gives a broader and more systematic understanding of aquifers (Lee, 1998). Various apparatuses are useful for physical modeling and chemical experiments.

Personal computers assist laboratory teaching in computer-assisted instruction, data visualization and analysis, and numerical or analytical modeling. Computerassisted instruction is a broad category where software partially or wholly replaces human instruction, becoming a tireless tutor (Renshaw et al., 1998). Most software is little more than an electronic textbook, which tests and guides students through scripted questions. More recently, computer-assisted instruction "experiment simulators" have been successfully applied to augment, but not replace, standard experiments, especially to prepare students before or summarize after the laboratory (Renshaw et al., 1998). Renshaw et al. (1998) showed that experiment simulators can be effective not only for increasing lower level cognitive skills but also higher order skills, such as cross-domain knowledge and critical thinking. Computer-assisted instruction software engages students in a pseudo-active manner, but gives students little appreciation of aquifer heterogeneity or the limits of data acquisition.

Visualization and analysis software has revolutionized our spatial understanding of the chemical and physical variability of aquifers (Hudak, 1998). A wide variety of data from water quality to aquifer tests is easily computed, plotted or graphed on personal computers, allowing students time to concentrate on the data collection or interpretation (Lee, 1998; Dunnivant et al., 2002). Software that displays 2-D or 3-D plots instantaneously presents interesting educational opportunities $(\mathrm{Hu}-$ dak, 1998). Although this plotting is not inherently more accurate, it is faster and easier for students to visualize. A first note of caution is that incorrect and incomplete data sets look just as good, especially on 3-D plots, as do good, complete data sets. Computer-derived plots can lull students into not inquiring about the data quality, which is a huge variable in any study. A second note of caution is that geostatistical analysis techniques should accompany any computer-assisted contouring. Geostatistical analysis techniques are taught in Geographical Information Systems and/or Spatial Analysis courses, but are often neglected in undergraduate hydrogeology courses. Students need instruction on how to critically evaluate their data and the resulting contour maps. An exercise demonstrating how one data set can be contoured to give quite different results is useful. Finally, hand contouring 
should not become a lost art. It is a useful skill because it allows for incorporation of hydrogeological information not explicitly present in the contoured data (Siegel, 2008). This approach, however, is not practical for large datasets.

Analytical and numerical modeling can help students understand the process and controls of groundwater flow and/or transport, and are useful vocational skills. Model complexity can range from highly simplified domains to complex models that integrate real field data (Rojstaczer, 1994; Haitjema, 2006). Macfarlane et al. (2006) develop contaminant transport software with a graphical user interface for a capstone educational experience, in which students take on the role of an environmental consultant.

Physical models, such as a "sand tank" apparatus, have been used as scaled aquifer models (Lee, 1998; Trop et al., 2000). A sand tank is a simple, clear plastic tank with a water input on one side and output on the other. Sand and/or gravel are aquifer materials, while silt or clay layers act as aquitards. Flow rate and style are controlled by altering the architecture of the layers. Introducing color dyes into the model aids in identifying the water table or visualizing contaminant transport. Physical models can be constrained by field trip observations and/or laboratory testing of physical parameters (Hudak, 1998; Lee, 1998; Trop et al., 2000). Students are most engaged when they derive the boundary conditions for a scaled model from their own data (Trop et al., 2000). Scaled models are useful for introductory classes to gain an understanding of flow dynamics, but overly simplify the heterogeneity of aquifers.

Even though chemical characterization of aquifers is important to researchers, especially considering water quality and contamination issues, little is published on the pedagogy of this topic. Fletcher (1994) outlined the purposes and general design of chemical characterization laboratories, but only Lee (1998) has provided concrete examples of chemical laboratory exercises. Dunnivant et al. (2002) briefly discussed pollutant fate, but primarily described a new computer-assisted instruction program, "Enviroland". Discussion on both the guiding principles and practical exercises for chemical hydrogeology laboratory exercises are needed.

The problems facing laboratory pedagogy are diverse, but are partially derived from the same problems as field pedagogy. First, aquifer heterogeneity and complexity wreak havoc on analysis and modeling of any aquifer, especially if real data derived from a field study are used in an introductory setting. Second, gigantic databases and the drive for three-dimensional visualization demand both diverse and complex software packages that are not easily learned (Hudak, 1998). Third, any scaling model is inherently inaccurate, and one must choose the variables which one hopes to model most accurately (Trop et al., 2000).

In conclusion, computer software and physical models are important and innovative learning tools in the hydrogeology laboratory. These can lead to greater understanding of the spatial limits and flow dynamics of aquifers. Ideally, computer software and physical models can use studentderived field data, which keeps students actively included and helps students remember the limitations of the data.

\section{Toward an integrated pedagogy}

To ensure the long-term sustainability of groundwater resources, we need to train a greater number of scientists and engineers who are versatile in both the theoretical and practical aspects of groundwater, and who can become responsible and knowledgeable scientists and citizens (Tinker, 1989; Fletcher, 1994). Many instructors of hydrogeology contend that field, laboratory and classroom components are all critical elements in a well-structured hydrogeology curriculum at all levels (e.g. Tinker, 1986; Fletcher, 1994). Many authors suggest that theory should be learned in the classroom and vocational skills should be taught in the field or laboratory (Lee, 1998). However, they offer few suggestions on classroom pedagogy or how to balance the components of field, laboratory and classroom. Learning of the three components ideally would be integrated into a cohesive, iterative whole, with data collection in the field and analysis in the laboratory, balanced with advances in theory in the classroom (Fig. 4). The three components would be organized in an iterative loop, in which advances in each component encourage, support and advance learning in the other two components. The allocation of instructional time and faculty resources between the three components will vary drastically between different topics, instructors, departments and institutions, depending on desired learning objectives and students. Furthermore, students should, as much as possible and where appropriate, derive their own data in the field, analyse these same data in the laboratory, and discuss the ramifications and meaning of their data and data analysis procedures in the classroom. In essence, we advocate that a balance be sought between theory and practical application, in which students are included in all components as owners of their data and their learning. To this end, we discuss how such an integrated curriculum encourages active learning and critical thinking, and we introduce methods and questions meant to encourage an integrated curriculum. To illustrate our view we first discuss two examples of this type of integration:

1. Trop et al. (2000) presented a well-structured example of integrating field, laboratory and classroom components. As previously described, pre-service teachers were taken on a field trip to make descriptions of an aquifer. With their field descriptions as boundary conditions, they were asked to build sand box models of their aquifer in the laboratory. Then these models were tested for accuracy, and the entire class discussed how to improve the models for greater accuracy before new models were created. This course established an iterative loop between the student-derived field data, studentcreated laboratory models, and instructor-led classroom 


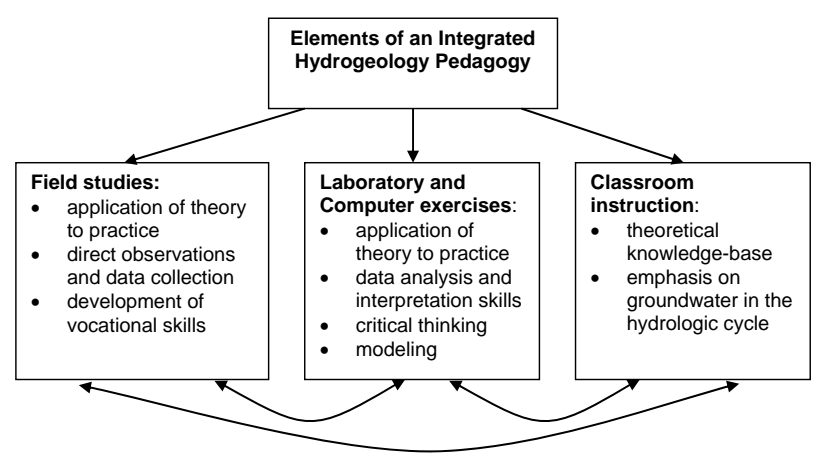

Fig. 4. The elements of an integrated hydrogeology pedagogy can be balanced in an iterative loop, so that each element supports other elements.

discussion. With this form of instruction, students are given an opportunity to collect field data and to apply the knowledge gained from their field observations to construct a representation or model of their aquifer. The aquifer model captures the key elements of the hydrogeological system, including the rivers and streams that act as boundary conditions. This example of a student-built scale model is ideal for pre-service teachers who receive limited instructional time. In a higher level course, field data could be used for mapping and graphing, or for the construction of a computer model that requires similar recognition of the boundary conditions.

2. Neupaurer (2008) developed a semester-long hydraulic containment design project that cumulatively builds students' understanding of the design problems through weekly assignments. This project is a good example of integrating laboratory and classroom activities, although it uses a hypothetical aquifer rather than real field data collected by students. Teams of students in an introductory undergraduate hydrogeology class complete weekly assignments such as drawing a water table map, calculating the hydraulic gradient, calculating hydraulic conductivity based on permeameter tests, slug tests, or pumping tests, and analyzing well logs to determine aquifer thickness, as these topics are covered in the course. For the final project, students use parameter values they have derived in their final design.

An integrated course that uses student-derived data naturally shifts towards an emphasis on active learning and critical thinking, key elements of experiential learning. By acquiring their own data, students become engaged in their learning, while developing critical vocational skills. An obvious method to include students in any laboratory exercise is to use only data that they themselves have measured or derived. This is a dramatic shift from pre-concocted exercises, which are easier to administer. The students learn to respect the limitations of the data, and feel inspired by their data ownership. Integrating this sort of data collection and interpretation offers a strong learning tool. Critical thinking is also a key element in the integrated approach in that students are asked to test their models for accuracy and recommend how the model could be improved.

This approach of having students collect their own data is not without its shortcomings. Due to the complexity of hydrogeological systems, the data collected by students will not always allow for analysis at a level appropriate for an introductory course in hydrogeology. Where this is a concern, other strategies for integrating a relevant field experience, such as a demonstration of data collection, supplementing collected data with existing data of known quality, or providing good quality raw data for use in subsequent analysis, should be considered.

Instructors of hydrogeology could consider the lecture room an extension of the laboratory and field, and vice versa. For example, the objective of the current week's laboratory exercise can be introduced at the beginning of a regular weekly lecture, with a question posed as to how the students might solve a particular problem. By the end of the lecture, the students should understand the relevant theory and have some idea about what the lab exercise will involve. Application to the real world should also be emphasized, by discussing case studies, showing photographs, or bringing in visual aids (e.g., samples of core and chip samples can be used effectively to demonstrate the difficulty in identifying lithology from small samples as well as the difficulty in identifying larger-scale heterogeneity and structure that may be evident in core or outcrop). Attendance of the instructor at laboratories and in the field act to reinforce the connection of the three areas. In this iterative loop the students understand the purpose to all three components, and can impart motivation and insight from one component to another component, where they may be lacking.

At an upper undergraduate level, students also benefit from large projects that span several weeks of laboratory instruction time. These projects might involve data collection, analysis and interpretation, and, ultimately, presentation of the findings in a report. Third year students at Simon Fraser University are given the task of interpreting hydrogeological data (constructing cross-sections, maps, etc.), analysing pumping test data, and synthesizing this information into a comprehensive hydrogeological consulting report over the course of four weeks. Feedback from both students and employers has been all positive. Not only do students learn how to assemble, present and interpret the data they collect, but they must also clearly articulate their findings. Such an exercise builds on much-needed writing skills, which ultimately will help to prepare the student for consulting or industry jobs or for thesis research at a graduate level.

A few simple, but significant, questions are useful when trying to make hydrogeology courses more integrated and active. Is what we are learning in the classroom linked thematically and does it support what we are learning in the field 
or laboratory? Or are the two disassociated? Are the students deriving their own data and is this same data set being used in laboratories and being discussed in the classroom?

\section{Conclusions}

We draw three overarching conclusions from our review of current practice that may be important for how we teach hydrogeology in the future:

1. Numerous advances in hydrogeologic pedagogy have occurred in the last fifteen years, but with a significant bias towards advances in field and laboratory teaching (Fig. 1). This has actually been the trend since the first hydrogeological pedagogy articles were published on laboratory methods (Brice and Levin, 1962; Lehr, 1963; Blanchard, 1964). At this watershed moment in pedagogy of hydrogeology, there is limited discussion about classroom pedagogy or debate about content in hydrogeology classes, at least in the peer-reviewed literature. The bias towards field and laboratory pedagogy may be due to the relative youth of hydrogeology pedagogy and/or due to the research and teaching interests of hydrogeologists, which lie predominantly in the field and laboratory.

2. The literature and survey results suggest there are relatively few topics that are considered essential in an introductory hydrogeology course (Fig. 2). Only $\sim 15$ topics are considered crucial by most hydrogeologists and $>100$ other topics are considered crucial by some hydrogeologists. Not surprisingly, the top 15 crucial topics focus on properties of aquifers and fundamentals of groundwater flow, and should likely be part of all undergraduate hydrogeology courses (Fig. 3). Other topics can supplement and support these crucial topics, depending on desired learning outcomes.

3. Students can learn these topics in a balanced and iterative loop of components of field, laboratory and classroom learning (Fig. 4). At the outset of this paper, we asked what form hydrogeology training should take and how to balance the need for theoretical knowledge and the need for vocational skills. Students can be exposed to all facets of the groundwater science - field, laboratory and theory - and they can learn to apply their data collection skills to their interpretive skills in such a way that a balance is attained between theory and practical application. An integrated hydrogeology pedagogy encourages active and experiential learning, which leads to greater student motivation and advancement of theoretical and vocational knowledge.
Supplementary material related to this article is available online at: http://www.hydrol-earth-syst-sci.net/ 16/2159/2012/hess-16-2159-2012-supplement.pdf.

Acknowledgements. B. Teswksbury is thanked for encouraging us to analyse the unpublished survey data. Two anonymous reviewers significantly improved this manuscript.

Edited by: T. Wagener

\section{References}

Alley, W. M., Healy, R. W., LaBaugh, J. W., and Reilly, T. E.: Flow and storage in groundwater systems, Science, 296, 1985-1990, doi:10.1126/science.1067123, 2002.

Bahr, J: O brave new world: geoscientists in an emerging green economy, GSA Today, 20, 12-14, 2009.

Banks, D., Younger, P. L., Arnesen, R.-T., Iversen, E. R., and Banks, S. B.: Mine-water chemistry: the good, the bad and the ugly, Environ. Geol., 32, 157-174, doi:10.1007/s002540050204, 1997.

Blanchard, F. N.: An electric analog model demonstrates groundwater flow, J. Geol. Educ., 12, 104-105, 1964.

Brice, J. C. and Levin, H. L.: Porosity and permeability experiments for general geology labratory, J. Geol. Educ., 10, 81-90, 1962.

Coontz, R.: Hydrogeologists tap into demand for an irreplaceable resource, Science, doi:10.1126/science.caredit.a0800120, 2008.

Davis, S. N. and DeWiest, R. J. M.: Hydrogeology, Wiley, New York, 1966.

Day-Lewis, F. D., Gray, M. B., Garfield, R. L., and Day-Lewis, A. D.: An on-campus well field for hydrogeophysics education and undergraduate research, Journal of Geoscience Education, 54, 480-486, 2006.

Domenico, P. A. and Schwartz, F. W.: Physical and chemical hydrogeology, Wiley, New York, 1998.

Dunnivant, F. M., Danowski, D., and Newman, M.: Teaching pollutant fate and transport concepts to undergraduate non-science majors, environmental scientists, and hydrogeologists using Enviroland, Journal of Geoscience Education, 50, 553-558, 2002.

Fetter, C. W.: Applied hydrogeology Prentice-Hall, Upper Saddle River, NJ, 2001.

Fletcher, F. W.: A hydrologic field laboratory for undergraduate instruction and research, J. Geol. Educ., 42, 491-493, 1994.

Foster, S. S. D. and Chilton, P. J.: Groundwater: the processes and global significance of aquifer degradation, Philos. T. Roy. Soc. B, 358, 1957-1972, 2003.

Freeze, R. A. and Cherry, J. A.: Groundwater Prentice-Hall Inc., Eaglewood Cliffs, NJ, 1979.

Fryar, A. E., Thompson, K. E., Hendricks, S. P. and White, D. S.: Incorporating a Watershed-Based Summary Field Exercise into an Introductory Hydrogeology Course, Journal of Geoscience Education, 58, 214-220, 2010.

Giordano, M.: Global groundwater? Issues and solutions, Annu. Rev. Env. Resour., 34, 153-178, 2009.

Gleeson, T., VanderSteen, J., Sophocleous, M. A., Taniguchi, M., Alley, W. M., Allen, D. M., and Zhou, Y.: Groundwater sustainability strategies, Nat. Geosci., 3, 378-379, 2010. 
Green, T. R., Taniguchi, M., Kooi, H., Gurdak, J. J., Allen, D. M., Hiscock, K. M., Treidel, H., and Aureli, A.: Beneath the surface of global change: Impacts of climate change on groundwater, J. Hydrol., 405, 532-560, doi:10.1016/j.jhydrol.2011.05.002, 2011.

Haitjema, H.: The Role of Hand Calculations in Ground Water Flow Modeling, Ground Water, 44, 786-791, doi:10.1111/j.17456584.2006.00189.x, 2006.

Halsor, S. P., Orem, B. F., and Rudenko, D.: A multi-media field laboratory and the development of an undergraduate methods course in subsurface hydrogeology, Geological Association of America, Abstracts with Programs 30, 307 pp., 1998.

Hiscock, K. M.: Hydrogeology: principles and practice, Blackwell, 2005.

Horner, T. C., Cornwell, K., and Kusnick, J.: Use of active learning modules in water quality and stream flow to enhance understanding of the scientific method, Geological Association of America, Abstracts with Programs 30, 1998.

Hudak, P. F.: Visualizing ground-water-flow fields and contaminant plumes in an undergraduate hydrogeology course, Journal of Geoscience Education, 46, 132-36, 1998.

Kolb, D. A.: Experiential learning: experience as the source of learning and development Prentice-Hall, New Jersey, 1984.

Laton, W. R.: Building Groundwater Monitoring Wells on Campus A Case Study and Primer, Journal of Geoscience Education, 54, 50-53, 2006.

Lee, M.-K.: Hands-on laboratory exercises for an undergraduate hydrogeology course, Journal of Geoscience Education, 46, 433438, 1998

Lehr, J. H.: Ground-water flow models simulating subsurface conditions, Journal of Geological Education, 11, 124-132, 1963.

Macfarlane, P. A., Bohling, G., Thompson, K. W., and Townsend, M.: Helping Students Make the Transition from Novice Learner of Ground-water Concepts to Expert Using the Plume Busters Software, Journal of Geoscience Education, 54, 610-619, 2006.

Mays, D. C.: One-Week Module on Stochastic Groundwater Modeling, Journal of Geoscience Education, 58, 101-109, 2010.

McCray, J. E. and Thyne, G. D.: Joint Sustainability of Petroleum Energy Production and Water Resources, Ground Water, 47, p. 611, doi:10.1111/j.1745-6584.2008.00540.x, 2009.

McKay, L. D. and Kammer, T. W.: Incorporating hydrogeology in a mapping-based geology field camp, Journal of Geoscience Education, 47, 124-130, 1999.

Neuman, S. P.: Comment on "Siegel, D.: Reductionist hydrogeology: ten fundamental principles. Hydrol. Process., 22, 4967-4970, 2008”, Hydrol. Process., 23, 1676-1677, doi:10.1002/hyp.7280, 2009.

Neupauer, R. M.: Integrating Topics in an Introductory Hydrogeology Course through a Semester-long Hydraulic Containment Design Project, Journal of Geoscience Education, 56, 225-234, 2008 .

Ngambeki, I., Thompson, S. E., Troch, P. A., Sivapalan, M., and Evangelou, D.: Engaging the students of today and preparing the catchment hydrologists of tomorrow: student-centered approaches in hydrology education, Hydrol. Earth Syst. Sci. Discuss., 9, 707-740, doi:10.5194/hessd-9-707-2012, 2012.
Pathirana, A., Gersonius, B., and Radhakrishnan, M.: Web 2.0 collaboration tools to support student research in hydrology an opinion, Hydrol. Earth Syst. Sci. Discuss., 9, 2541-2567, doi:10.5194/hessd-9-2541-2012, 2012.

Pederson, D.: Education and employment in hydrogeology, J. Geol. Educ., 35, 16-21, 1987.

Renshaw, C. E., Taylor, H. A., and Reynolds, C. H.: Impact of computer-assisted instruction in hydrogeolgy on critical-thinking skills, Journal of Geoscience Education, 46, 274-279, 1998.

Rimal, N. N. and Stieglitz, R. D.: Using available resources to enhance the teaching of hydrogeology, Journal of Geoscience Education, 48, 508-513, 2000.

Rodhe, A.: Physical models for class-room teaching in hydrology, Hydrol. Earth Syst. Sci. Discuss., 9, 4135-4160, doi:10.5194/hessd-9-4135-2012, 2012.

Rojstaczer, S.: The limitations of groundwater models, J. Geol. Educ., 42, 362-368, 1994.

Sanders, L. L.: Teaching hydrogeology to undergraduate and graduate students, Geological Association of America, Abstracts with Programs 30, 305 pp., 1998.

Santi, P. M. and Higgins, J. D.: Preparing Geologists for Careers in Engineering Geology and Hydrogeology, Journal of Geoscience Education, 53, 512-521, 2005.

Schwartz, F. W. and Zhang, H.: Fundamentals of Ground Water, Wiley, New York, 2003.

Siegel, D: Reductionist hydrogeology: ten fundamental principles, Hydrol. Process., 22, 4967-4970, 2008.

Siegel, D. and McKenzie, J. M.: Contamination in Orangetown: A Mock Trial and Site Investigation Exercise, Journal of Geoscience Education, 52, 266-273, 2004.

Singha, K.: An Active Learning Exercise for Introducing GroundWater Extraction from Confined Aquifers, Journal of Geoscience Education, 56, 131-135, 2008.

Sophocleous, M: Interactions between groundwater and surface water: the state of the science, Hydrogeol. J., 10, 52-67, 2002.

Tinker, J. R. J.: Technical writing in hydrogeology, J. Geol. Educ., 34, 25-27, 1986.

Tinker, J. R. J.: Undergraduate education in hydrogeology, J. Geol. Educ., 37, 20-23, 1989.

Todd, D. K.: Groundwater hydrology, Wiley, New York, 1980.

Trop, J. M., Krockover, G. H., and Ridgway, K. D.: Integration of field observations with laboratory modeling for undergraduate hydrologic processes in an undergraduate earth-science course, Journal of Geoscience Education, 48, 514-520, 2000.

Wagener, T., Kelleher, C., Weiler, M., McGlynn, B., Gooseff, M., Marshall, L., Meixner, T., McGuire, K., Gregg, S., Sharma, P., and Zappe, S.: It takes a community to raise a hydrologist: the Modular Curriculum for Hydrologic Advancement (MOCHA), Hydrol. Earth Syst. Sci. Discuss., 9, 2321-2356, doi:10.5194/hessd-9-2321-2012, 2012.

Younger, P. L.: Groundwater in the environment, Blackwell, 2007. 